University named after T. Shevchenko. Chernihiv: ChTPU. 54. 190-193.

4. Misharovsky, R.M. (2011). Method of differentiated training of motor skills of junior schoolchildren in the course of football studies(Ph.D Dissertation of Physical Culture, Fundamentals of Health). Thesis. Kiev: NPU named after MP Drahomanova. $21 \mathrm{p}$.

5. Shamardin, V.M. (2013). Technology of management of the system of long-term training of football teams of higher qualification (Doctor Sciences Dissertation of Physical Culture, Fundamentals of Health). Thesis. Lviv: LSUFK. 35 p.

6. Brooks, D.S. (1997). Program design for personal trainer: Bridging theory into application. Human kinetics. $328 \mathrm{p}$.
7. Mekota, K. (1984). Test pohylove koordinace a rovnovahy. The or und Praxeder Korperkultur. 2. 18-25.

8. Zimmermann, K., Hickisch, R. (1981). Die Ausbildung koordinativer Pahegkelten nd ihre Bedeutuny fur die technischebzw techniscl-taktische Leistungstahigkeit der Sportier. Theorie und Praxis der Korperkultur. 10. 746-768.

9. Braunwald, E. (1992). Heart Disease. A Textbook of Cardiovascular Medicine. W. B., Saunders Company. 4 edit. Philadelphia. 2.

10. Hirtz, Pr., Wellnitz, J. (1985). Hohes Niveau koordinativer Pahigkeiten fuhrt zu besaeren Brgebnsen im motoriechen Lemen. Ibid*. 154-155.

KUTSENKO Alexey,

postgraduate,

Gregory Skovoroda State Pedagogical University of Pereyaslav-Khmelnytsky

\title{
AGE FEATURES OF COORDINATION AND TECHNICAL PREPARATION OF JUNIOR SCHOOLCHILDREN AT THE INITIAL STAGES OF FOOTBALL TRAINING
}

Abstract. It has been determined that as a result of inconsistency of volumes of motor activity and purposeful provision of the training effect, the functional state of various body systems of the majority of children and adolescents during the school education is not ensured by the formation of the necessary reserves during the period of active biological and mental development, which leads to pathology in a state schoolchildren's health.

This situation can be corrected by the introduction of additional or lessons or football lessons, but the content of the relevant classes does not provide for the age-specific features of the formation of the technical-coordination foundation and has no scientific substantiation.

The age characteristics of the development of technical coordination qualities were studied and the most prioritized indicators of appropriate preparedness were determined.

From 7 to 8 years the greatest dynamics of components of technical coordination of younger schoolchildren, additionally engaged in football, recorded in the indica- tors: juggling by the ball-90,0\%; ring throws on a tripod from a distance of $1.5 \mathrm{~m}$ to $3.5 \mathrm{~m}$-from $41.9 \%$ to $56.0 \%$; strikes on the ball for accuracy - 37,8\%; stopping the ball with the sole-35.9\%;

The most positive changes in the state of development of technical-coordination qualities of boys from 8 to 9 years are observed in the indicators: the course on the straight line with closed eyes - 50,6\%; stopping the ball with the sole - 16.0\%; strikes on the ball for accuracy $16.0 \%$;

The results of changes in younger schoolchildren from 8 to 9 years on the indicators of the Flamingo test, the outline of the rings on a tripod at a distance of $1.5 \mathrm{~m}$ and the definition of muscle feeling is not credible.

Keywords: schoolboy; health; football; coordination qualities; technical training.

Одержано редакиією 17.01.2019 Прийнято до публікаиіï 21.01.2019

DOI 10.31651/2524-2660-2019-2-210-214

ORCID 0000-0002-5904-5137

КУРХАН Мурат Абдумгамит огАу,

докторант кафедры педагогики и психомогии, Бакинский славянский университет, Азербайджан e-mail: bitkovskayay@inbox.ru

УДК 378.146

\section{ОБ ОЦЕНКЕ ДОСТИЖЕНИЙ УЧАЩИХСЯ В ОБЩЕОБРАЗОВАТЕАЬНЫХ ШКОААХ}

В наше время одной из наиболее актуальных проблем теоретической педагогики и педагогической практики является мониторинг и оиенка деятельности общеобразовательных школ, ее сотрудников, а также достижений учеников. При проверке знаний, умений и навыков школьников большое значение имеет их объективная оченка, при этом во всех школах должен быть единый подход к определению качества успеваемости. Проблема эта не простая, особенно если учесть, ито оиенка знаний выступает в качестве тонкого и весьма острого инструмента воздействия на учашихся. Высокая оиенка знаний может и воодушевлять школьника к учению, но может и расхолаживать его. Еше сильнее воздействует неудовлетворительная оиенка: она может и побуждать школьника к усилению своей учебной работы, и отбивать охоту к учению. ключевые слова: учитель; ученик; межличностные отношения; педагогика; общение; оиенка достижений.

Постановка проблемы. В настоящее время в области образования осуществляются целенаправленные реформы с точки зрения современных требований. Реформирование структуры системы образования, ее содержания, материально-технической базы, управления в соответствии с требованиями образовательных стандартов, разработка новых нормативно-правовых документов, обеспечивающих мониторинг и оценку резумьтатов в системе образова- 
ния (особенно в общеобразовательных школах), по-прежнему актуальны, и обеспечение качества в системе образования и его дальнейшее развитие явцяются серьезной пробцемой.

Цемь статьи - рассмотреть оценки достижения учащихся в общеобразовательных школах.

ИзАожение основного материама. Решение этих проблем и успешное осуществление данной цели требуют создания материально-образовательной базы школы, квалифицированных и компетентных руководителей, учителей с достаточной теоретической и практической подготовкой, учебной программы, адаптированной к требованиям современной эпохи, учебного процесса, ориентированного на студентов, системы оценки деятельности учебного заведения и достижения в области обучения.

Важные изменения и нововведения были начаты в рамках широкомасштабного реформистского движения в области образования во всем мире, и эти работы продолжаются успешно. ГАавная цель реформ - это создание универсальной, светской системы образования, соответствующей современным стандартам. Поэтому, основываясь на принципах демократизации, гуманизации, гуманитаризации, дифференциации и интеграции в образовании, формирование мичности педагога как основного субъекта обучения, главной целью которого является объединение мониторинга и оценки в образовании, направленное на объединение деятельности всех учреждений в интересах педагогов, моделирование, разработка новых подходов к обеспечению координации его отдельных структурных подраздемений имеют большое значение, как с научной, так и с практической точки зрения. Воспитать человека с обширными знаниями, навыками и способностями, независимым, высоким моральным и нравственным характером создает необходимость в разработке новых подходов к оценке воспитательно-учебной работы, мониторингу деятельности руководителя и сотрудников учебного заведения, учебных достижений обучаемых в системе образования [1, с. 31-32].

Одной из наиболее актуальных проблем теоретической педагогики и педа- гогической практики явцяется мониторинг и оценка деятельности общеобразовательных школ, ее сотрудников и менеджеров, а также успехов учеников в наше время. Измерение качества и эффективности обучения в различные периоды развития общества, а также результаты измерений всегда были главной проблемой для работников образования. Если теоретический аспект проблемы представляет больший интерес для ученых, уровень обучения в учебных заведениях и оценка успеваемости учащихся больше тревожит педагогов и учителей.

Поэтому успешное выполнение основных задач, стоящих перед учебными заведениями с точки зрения современных требований, требует создание новой нормативно-правовой базы, более эффективного использования финансовых ресурсов, обновление содержания образования, обеспечение качества государственных учреждений, специальный мониторинг, точную оценку процесса, опредемение государственносоциального и государственногосударственного характера управления, создание новых систем сертификации, мицензирования, аттестации и аккредитации, а также успешное решение других важных вопросов.

Необходимость более точного и объективного измерения качества в таких подходах и необходимость создания научно обоснованного, нового, надежного механизма оценки дия эффективности работы предприятия, по-видимому, является требованием дня. Дия этого, прежде всего, особенно важно рассмотреть существующие научнотеоретические подходы в области оценки, содержания и формы учебнообразовательного процесса, определить показатели, характеризующие деятельность участников процесса, и точно вычислить их весовое соотношение (уровень значимости) в реальном процессе, оценить решающую роль образования в системе образования [2, с. 65].

Анализ теоретико-педагогической и методологической митературы показывает, что поскольку использование систематических, цеменаправиенных научнопедагогических подходов к мониторингу и оценке в общеобразовательных школах не достигнуто, показатели качества 
школьного учебного процесса сокращаются. В последние годы были проведены различные образовательные исследования по проблеме мониторинга и оценки в системе образования, и хотя из полученных результатов были сделаны ценные предможения и суждения, они не были своевременно доведены до общественности и результаты не были достигнуты [1, с. 35$]$.

По проблемам мониторинга и оценки в системе образования в XX веке ученые педагоги из США, Великобритании, Германии, Израиля, такие как Н. Дуталь, П. Мортимор, П. Самонс, В. Хой, К. Мискель, Г.Б. Колеман, Х. Газиэль, К.Т. Фиц-Гиббон, М. Коэн, Дж.Х. Стронк, Д.А. Стафебем, а также из российских педагогов В.И. Андреев, В.П. Беспалько, В.А. Кални, А.Н. Майоров, С.Е. Шишов и другие провели обширные исследования, попытались интерпретировать проблему с научно-педагогической точки зрения и сделали замечательные комментарии по этому поводу.

Разработка научно-педагогических, психологических и методологических основ существующих проблем модернизации системы образования, внедрение образовательного и учебного процесса на основе демократических принципов, повышение независимости учебных заведений, укрепление национальной основы в образовании, обеспечение универсальных и мирских ценностей дмя образования, педагогический мониторинг и оценка результатов являются ключевыми показателями, которые определяют их актуальность.

В настоящее время педагогический процесс требует, чтобы каждый участник процесса (ученики, учителя, родите$\Lambda и$, органы управления образованием и т. д.) размышлял, действовал и добивался качественных изменений в образовании. Долгое время управление общеобразовательными школами основывалось на системе централизации, школа была отделена от общества, ее производительность оценивалась очень простым способом. В этом случае оценка работы общеобразовательных школ осуществляется высшими учебными заведениями и, по сути, носит ревизионный характер и служит только для выявления недостатков. Это приводит к формированию системы управления в учебном заведении. Хотя система управления повышает ответственность руководителей средних школ, она фактически служит дия управления школой, а не для развития школы. Таким образом, такая форма управления не помогла улучшить качество образования.

Именно по этой причине форма управления должна быть улучшена для обеспечения того, чтобы общеобразовательные школы получали эффективные результаты, руководство школы должно быть непосредственно связано с процессом обучения, все его поля (содержание, способы, учебная среда, сама система оценки и т.д.), а также педагогический процесс должен участвовать в оценке деятельности основных заинтересованных сторон - учеников, учителей, родителей и органов управления образованием. В этом случае информационный носитель общеобразовательной школы, участники учебного процесса, учителя, студенты и их родители должны активно участвовать в этом процессе.

Если контроль над ответственностью директоров школ возникает из-за открытости и прозрачности, оценка результатов становится стимулом дця работы участников педагогического процесса. Оценка достижений школ и учителей в реализации образовательных цемей в этом подходе и новый инструмент оценки и методомогическое обоспечение для создания диалога с другими органами образования составцяют основу работы [3, с. 215].

Как мы уже отметили, оценка позвомяет нам получать информацию о ходе и результатах учебного процесса, отслеживать динамику учащихся, влияет на формирование кичности у студента, воспитывает критическое отношение к своим успехам и достижениям товарищей, повышает чувство ответственности у каждого учащегося. Оценка достижений учащихся также важна с психомогической точки зрения. Во время процесса оценки активизируется мышление учащихся, укучшается память, развивается могическое мышление и чувство ответственности при анализе практических вопросов. Оценка дейятельности и результатов обучения учащихся также имеет общегосударственное значение. 
Поэтому особое внимание смедует удемять следующим вопросам в процессе оценки:

- зависимость результатов обучения от местонахождения шкомы, ее территория, социальный статус насемения, находящегося на данной территории, принадлежность ее городской ими семьской школе, количество обучаемых мальчиков и девочек, языковые группы, принадмежащие ученикам;

- вопрос о том, какие ученики симьны и слабы в школьной учебной программе, вАияние изменения содержания на учебный процесс;

- необходимость изменения стандартов показателей учащихся на основе результатов обучения предметам;

- анализ характера и особенностей корреляции между достижениями в обмасти обучения учащихся предметам в разных городах, отдемьных регионах и сельских школах и подготовка соответствующих предложений.

Чешский

педагог-гуманист Я. Коменский когда-то отметиц противоречивый характер оценивания и обратился к учителям с призывом использовать его с умом и осторожностью. Во время оценки знания учеников, требование соответствия объективности с гуманным отношением домжно привлекать всю дидактическую систему и состав-

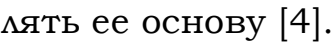

Если обобщить эти идеи, можем сказать, что правимьный подход учителя к оценке успеваемости учащихся является кАючевым фактором. Это требует от учителя высокой профессиональной компетентности и мастерства. Много-

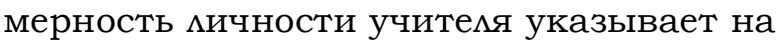
то, что индивидуальный стиль работы учителя, его поведение и отношение разностронны. В.Н. Сорока-Росинский демит учителей на четыре основных типа: учитель-теоретик, педагог-реалист, учитель-утилитарист, учитель-артист.

В.Н.Сорока-Росинский считает, что у первых теория и идея всегда доминируют в ущерб реальному миру вещей и практике. Вторые, наоборот, слабы в теории, но умемо чувствуют настроение учеников. Утилитаристы напоминают реалистов своими эмпирическими взглядами, но их девиз такой: следует проводить последоватемьную подготовку дия укрепления пройденного материала. Дия них весь мир - получить образование,

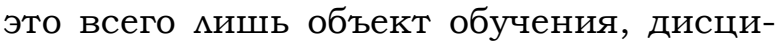
плина. Учителя-артисты работают над эмоциональными проблемами, интуицией и вдохновением. Они отмичаются своим творческим подходом к уроку, независимостью в своих мыслях, искренностью в своих чувствах и сильным влиянием на образование учащихся. Однако, в зависимости от их настроения, иногда они проводят неинтересные уроки, а иногда они плохо готовятся к урокам [5].

Е.Г. Костяшкин фокусирует внимание на следующих четырех психологопедагогических типах учителей: интелмектуальном, волевом, эмоциональном и организационном типах. На основании того ими иного типа очевидно, что какой умственный процесс или их структура превосходит.

Согласно новому педагогическому мышлению, учителя домжны быть способны заинтересовать и удивить студентов. По мнению азербайджанского классического философа Бахманьяра, мышмение начинается с удивмения. Кто не удивмяется, у него мышление не развивается. Эти слова имеют глубокую истину. Учащиеся должны быть заинтересованы в предметах, преподаваемых в школах, темах и составе педагогов.

Кроме того, учитемь, который вмадеет педагогическими навыками, опредемяет свои идеи, выводы, принципы в адекватной могике педагогических идей, рассматриваемых в теории преподавания и воспитания, правимьной идентификации предмета и событий, определении категории психолого-педагогических концепций, основных педагогических задач (задач) и его оптимальных дия опредемения методов решения.

Когда учитель основывается на научной теории и передовом педагогическом опыте в своей работе, его умение совершенствуется. По мнению А. Макаренко, студенты готовы простить учителям их серьезность, черствость и даже неуместное замечание, но они не прощают их за незнание своей работы. Вемикий педагог, говоря о педагогическом мастерстве, писал: "Я на опыте пришем к убеждению, что решает вопрос 
мастерство, основанное на уменье, на квалификации" [6].

Выводы и перспективы дапьнейших исследований. По нашему мнению, школьная оценка результатов достижений учащихся является единственным педагогическим инструментом, который помогает регулировать педагогический процесс, улучшать его качество, а также обучать педагогов существующим недостаткам и информировать родителей. В этой связи правицьная организация оценки достижений учащихся и четкая цемь при оценке играют важную роль в получении точной информации о качестве образования и его продвижении.

\section{Список бибниографических ссынок}

1. Беспалько В.П. Мониторинг качества обучения средство управления образованием. Мир образования, 1996. № 2. С. 31-36.

2. Абасов 3. От оценки учителя к самооценке ученика. Директор школы, 1999. №2. С. 63-71.

3. Persson E.L., Miller K.S., Nieman J.A., Sgourakis A.P., Akkerman S.R. Formulary evaluation using a class review approach: Experience and results from an academic medical center. P.-T. 2013. 38(4). 213-216.

4. Коменский Я.А. Избранные педагогические сочинения: В 2-х т. Т.1. Москва: Педагогика, 1982. $656 \mathrm{c}$.

5. Типы учителей. URL: https://studme.org/46516 /pedagogika/tipy_uchiteley (Дата обращения: 05.10.2018)

6. Макаренко А. Некоторые выводы из моего педагогического опыта. URL: http://pedagogia.pro/ node/422 (Дата обращения: 18.09.2018)

\section{References}

1. Bespalko, V.P. (1996). Monitoring the quality of education - a means of managing education. World of Education. Moscow. 2. 31-36.

2. Abasov, 3. (1996). From teacher assessment to student self-assessment. Head teacher. 2. 63-71.

3. Persson, E.L., Miller, K.S., Nieman, J.A., Sgourakis, A.P., Akkerman, S.R. (2013). Formulary evaluation using a class review approach: Exper?ence and results from an academic medical center. P.-T. 38(4). 213-216.

4. Komensky, Ya.A. (1982). Selected pedagogical writings: In 2 Volums. Vol. 1. Moscow: Pedagogy. $656 \mathrm{p}$.

5. Types of teachers. Retrieved 05/10/2018, from https://studme.org/46516/pedagogika/tipy_uchite ley.

6. Makarenko, A. Some conclusions from my teaching experience. Retrieved 09/18/2018, from http:// pedagogia.pro/node/422

\section{KURHAN Murat,}

post-graduate student of the department Pedagogy and psychology,

\section{Baku Slavic University, Azerbaijan}

\section{ABOUT THE ASSESSMENT OF ACHIEVEMENTS OF PUPILS IN GENERAL SCHOOLS}

Abstract. In our time, one of the most pressing problems of theoretical pedagogy and pedagogical practice is the monitoring and evaluation of the activities of general education schools, its employees, and the success of students. When checking the knowledge, skills and skills of schoolchildren, their objective evaluation is of great importance, and in all schools, there should be a unified approach to determining the quality of academic performance. This problem is not simple, especially considering that the assessment of knowledge serves as a subtle and very acute tool for influencing students. A high assessment of knowledge can and inspire the student to study, but can also discourage him. The unsatisfactory assessment is even more effective: it can also prompt the student to strengthen his academic work, and to discourage the pursuit of learning.

The purpose of the article is to disclose and analyze assessment of student achievement in general education schools.

The methods of the analysis, synthesis, abstraction are used in the article.

Results. The pedagogical biography of each teacher is different. No teacher at all becomes a master teacher at once. It takes some time. To be masterful, creative, the teacher must know and understand the legality and mechanism of the pedagogical process. This helps the teacher to acquire and manage pedagogical thinking. As a result, the teacher must independently analyze pedagogi- cal events and manifestations. They form the ability to classify, systematize, summarize and summarize.

Originality. The main purpose of assessing students' achievements is to study the current state of their knowledge and skills in the school, the region and the country, to improve the process of training and education and ensure dynamic development. Such a systematic assessment of knowledge and skills enhances the content of the subject of study, improves the curriculum, improves the independence and participation of students, helps them work with textbooks and other educational materials, analyze the information received, better understand and apply educational materials.

Conclusion. School assessment of student achievement is the only pedagogical tool that helps regulate the pedagogical process, improve its quality, as well as educate teachers on existing shortcomings and inform parents. In this regard, the proper organization of the assessment of student achievement and a clear goal in the evaluation play an important role in obtaining accurate information about the quality of education and its promotion

Keywords: teacher; pupil; relationships between people; pedagogical intercourse; assessment of achievements. 